\title{
A biodiversidade como atrativo turístico: o caso do Turismo de Observação de Aves no município de Ubatuba (SP)
}

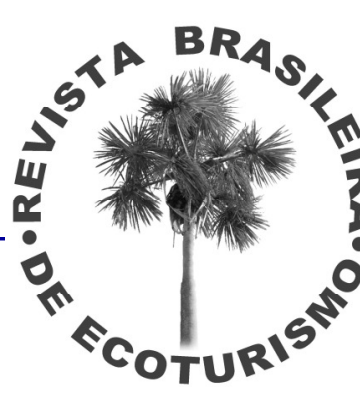

\section{Reinaldo Dias}

\section{RESUMO}

Este artigo analisa a importância do segmento turístico de observação de aves. Descreve a importância que vem assumindo a observação da fauna em várias partes do mundo. Identifica as possibilidades econômicas de exploração desse segmento como alternativa de renda para as comunidades locais. Descreve o desenvolvimento do Turismo de Observação de Aves em Ubatuba/SP, a parceria com o setor privado local, seu significado para o município e os desdobramentos para outras localidades. Finalmente identifica e destaca os aspectos positivos da observação de aves para a sustentabilidade do ecossistema local

PALAVRAS-CHAVE: Ubatuba; Turismo de Observação de Aves; Sustentabilidade, Biodiversidade.

Biodiversity as touristic atractive: the case of Bird Watching Tourism in Ubatuba city (SP), Brazil

\section{ABSTRACT}

This article examines the importance of the tourist segment of bird watching. It describes the importance that the observation of fauna has been assuming in various parts of the world. It identifies opportunities for economic exploitation of this segment as an alternative income for local communities. It describes the development of bird watching tourism in Ubatuba (SP), Brazil, and the partnership with the local private sector, its significance to the municipality and the consequences to other locations. Finally, it identifies and highlights the positive aspects of birdwatching for the sustainability of the local ecosystem.

KEYWORDS: Ubatuba; Birdwatching Tourism; Sustainability; Biodiversity.

\section{Introdução}

O turismo com base na natureza é um dos segmentos que mais cresce em todo o mundo, e sua tendência é continuar em ascensão em virtude do interesse despertado pelos temas ambientais. São várias as circunstancias que levam as pessoas a privilegiarem esse tipo de lazer, entre as quais estão: o aumento da consciência da importância da preservação dos recursos naturais; a necessidade psicológica das pessoas de encontrarem alternativas de lazer diferentes das praticadas nos grandes centros urbanos; maior aproximação com as formas simples de vida em contraposição à complexidade da vida moder- 
na nos grandes centros urbanos e; busca de melhor qualidade de vida, que se traduz como uma maior interação com a natureza.

Como decorrência os destinos turísticos que apresentam riqueza de diversidade podem apresentar uma vantagem comparativa em relação a outros, quando desenvolvem uma estratégia bem elaborada voltada para determinado público. Embora o Brasil apresente uma grande riqueza em termos de biodiversidade não se tem beneficiado de um aumento do fluxo de turistas internacionais. Os problemas que afetam esse tipo de turismo são, basicamente, os mesmos dos outros segmentos mais tradicionais: falta de infraestrutura, baixa capacitação da mão-de-obra, falta de sinalização, ausência de medidas de segurança, falta de investimentos, promoção insuficiente etc.

No entanto, alguns municípios brasileiros têm obtido sucesso na captação de turistas tendo como atrativo seus recursos naturais, destacando-se no cenário nacional o caso de Bonito no Mato Grosso do Sul, entre outros.

Um caso de aproveitamento de um recurso natural específico, no caso aves, será abordado neste trabalho. Considerado um nicho de mercado, o Turismo de Observação de Aves ou de observação de aves, constitui uma das atividades que estão em acelerado crescimento em todo o mundo, pois envolve de modo concreto o visitante com uma prática ecológica que antecede e se estende muito além da visitação, exigindo preparo, planejamento e posterior avaliação.

O Turismo de Observação de Aves além de elevar e consolidar o grau de conscientização ecológica do visitante torna-se importante instrumento de educação ambiental para a população residente, em particular, a população mais jovem. É uma atividade que exige conhecimento especializado em ornitologia, levantamentos periódicos da população de aves, identificação das espécies, e integração em diversas redes de acompanhamento de grupos específicos de aves, além da particularidade de recepção de turistas diferenciados, com alto nível de exigência de qualidade no atendimento de seus interesses, além de uma perfeita sincronização dos períodos de visitação nos locais que oferecem as meIhores condições de visualização de espécimes.

Levando-se em consideração essas características, o artigo procura analisar o caso de Ubatuba, município localizado no Estado de São Paulo, e que apresenta uma das áreas de Mata Atlântica mais preservadas do país e que vem obtendo sucesso na captação de observadores de aves internacionais.

\section{A observação de aves}

Há diversos tipos de produtos turísticos que podem ser enquadrados como turismo com base na natureza, como aqueles que buscam a observação de animais na natureza, a vivência em ambientes naturais, caminhadas por vias seguras, apreciação de paisagens naturais entre muitas outras. Esse tipo de turismo apresenta um amplo leque de tipologias, tais como: ecoturismo, turismo rural, turismo de aventura, turismo ambiental, turismo de observação de aves, espeleoturismo entre outros.

O turismo com base na natureza constitui uma das grandes tendências da ativida- 
de turística mundial, e que se fortalece com o aumento da consciência ambiental. Constituem ideias-força importantes dessa busca pela natureza, lugares naturais idílicos, a visão de animais selvagens em seu ambiente natural, o sentimento de que sua presença contribui de alguma forma para a preservação, entre outros. Essas ideias-força no seu conjunto formam o imaginário do turista que busca a natureza como forma de lazer. Nesse contexto, a fauna constitui um importante atrativo turístico, um recurso endógeno valioso das localidades que a possuem e se devidamente planejado pode resultar em benefícios para a população, maximizados pelo fato de serem obtidos por uma atividade sustentável.

Há países, regiões e localidades ao redor do mundo que descobriram o potencial turístico da fauna, onde os animais têm muito mais valor econômico vivos do que mortos. Estudos revelaram que um único leão do Parque Nacional Amboseli do Quênia tem um valor de turismo equivalente a US\$27.000 anuais, enquanto uma manada de elefantes atrai US\$610.000 anuais (LINDBERG, 1991; BOO, 1990 apud EDROMA,1997). Os gorilas do Parque Nacional de Virunga, em Ruanda, contribuíram para o recolhimento de uma renda líquida de US\$4 milhões. Países como Costa Rica, Equador, Belize, Quênia, Tanzânia e África do Sul "são alguns exemplos em que o turismo de natureza, centrado na observação da vida silvestre,é responsável por quase totalidade da receita turística internacional" dessas nações (BRASIL, 2005).

Nos Estados Unidos, a observação de vida selvagem envolve milhões de pessoas e gera bilhões de dólares. De acordo com o órgão responsável pela caça e pesca norteamericano, 66 milhões de residentes ou 31\% da população dos Estados Unidos de 16 anos ou mais, fotografa e observa a vida selvagem gastando 38,4 bilhões de dólares nessa atividade. Essas atividades incluem alimentação de aves e outros animais selvagens (54 milhões), observação de vida selvagem (42 milhões) e fotografar vida selvagem(14 milhões). Um terço de todos os observadores de vida selvagem, ou aproximadamente 22 milhões de pessoas, viajam com o propósito primário de participarem de atividades recreativas que envolvem observação de vida selvagem. Em 2001, os observadores de vida selvagem gastaram 8,1 bilhões de dólares nessas viagens, com comida e hospedagem, transporte, e outros custos de viagem (USA, 2002).

Em alguns pontos do país se explora a observação de baleias que é realizado tendo o cuidado de não prejudicar a vida animal. O turismo de observação de baleias (Whale -watching) quando bem planejado oferece oportunidades de renda para um número maior de pessoas do que a antiga e condenável prática de caça a esses animais. No Brasil, a observação de baleias é realizada com monitoramento permanente e constante em dois pontos principais.O primeiro no litoral de Santa Catarina, monitorada pelo Projeto Baleia Franca, que acompanha a espécie Baleia Franca Austral (Eubalaena australis); e o segundo no Parque dos Abrolhos, no litoral sul da Bahia, com acompanhamento pelo Instituto Baleia Jubarte, que estuda a Baleia Corcunda (Megaptera novaeangliae).

Esse fato, da biodiversidade apresentar valor econômico em seu próprio ambiente natural, sem nenhuma transformação, traz como consequência a possibilidade de que ela própria (a biodiversidade) possa converter-se numa ferramenta ideal para a sua própria conservação. 
Um dos tipos de turismo de observação da fauna que mais se desenvolvem em todo o mundo, é o de observação de aves (turismo ornitológico, ou bird-watching) e que demanda um esforço de marketing por parte dos destinos que apresentam em algum grau uma presença de espécies carismáticas ou uma diversidade significativa de muitas outras.

Nesse contexto, a prática da observação da fauna é considerada a atividade mais sustentável entre todas as que são identificadas com o ecoturismo, e dentre estas a observação de aves (bird-watching) constitui a mais difundida e a mais amplamente praticada no mundo todo, principalmente, nos países desenvolvidos. Nos Estados Unidos, em 2001, aproximadamente 46 milhões de todos os observadores de fauna (69\%) eram observadores de aves (USA, 2002). Há um crescimento contínuo do número de observadores de aves nos Estados Unidos que pode ser constatado pelo crescimento de vendas dos guias de identificação de aves, no número de festivais realizados em todo território norte-americano (mais de 200), além dos dados numéricos fornecidos periodicamente pelo Serviço de Pesca e Vida Selvagem. Segundo Cordell e Herbert (2002) as comunidades estão adotando vários caminhos para atrair os observadores de aves para suas cidades, pois reconhecem que estes visitantes gastam dinheiro em transporte, hotéis, restaurantes, guias locais, e suvenires; o que significa que enquanto os observadores de aves levam lembranças para seus locais de origem, eles deixam para a localidade rendas para os negócios locais.

As localidades que possuem em seu território áreas propícias para observar aves, tanto pelas suas características de biodiversidade ou alto grau de endemismo, deveriam procurar transformar essa riqueza natural em recurso econômico através do ecoturismo de observação, para melhorar a qualidade e o nível de vida de seus habitantes. A população ao compreender a importância da proteção dessas áreas, evitará sua depredação que ocorre através de inúmeras ameaças (queima, caça, turismo predatório etc.).

Os observadores de pássaros através de sua prática têm a oportunidade de converter lugares desinteressantes, mal utilizados ou sem interesse econômico em destinos que poderão contribuir para o desenvolvimento da região. Haverá uma valorização de áreas, com um aproveitamento racional de recursos naturais de modo sustentável.

Há inúmeras vantagens em se incentivar a observação de aves, entre as mais importantes encontra-se o fato de tratar-se de atividade de baixo impacto ambiental, pois de um modo geral, "quem observa aves se desloca nos ambientes naturais em pequenos grupos, caminhando de forma discreta e silenciosa, anotando as espécies vistas, gerando o menor impacto possível no local' (FARIAS, 2007 p.474).

O território brasileiro pela abundância de biomas, que propiciam a existência de inúmeros ecossistemas, é bastante rico em aves, e provavelmente possui ainda um número significativo não descrito pela ciência tornando-se, portanto, um local bastante propício para receber um grande contingente de birders internacionais, e fomentar o desenvolvimento do hobby entre os brasileiros. Há uma importante ferramenta para a prática do birdwatching no Brasil, que é o site wiki-aves (www.wikiaves.com.br), reúne a maior comunidade on-line de observadores de aves do Brasil, que na forma de colaborações constroem um banco de dados, permanentemente atualizado, com fotos, sons e informa- 
ções sobre as espécies de aves brasileiras.

A observação de aves, em particular, apresenta inúmeros impactos positivos (SEKERCIOGLU, 2002: p.284):

- Atrai incentivos financeiros para a conservação da vida selvagem.

- Gera menos impacto e maior renda do que o turismo tradicional

- Aumenta o controle local,quando da ocorrência de espécies únicas de aves.

- Ocasiona visitação de áreas fora dos itinerários turísticos tradicionais.

- Melhora a proteção de áreas não protegidas institucionalmente que contenham espécies desejadas.

- Promove a valorização do conhecimento local de história natural.

- Fomenta a educação e emprego de guias locais.

- Propicia a formação de fundos para a conservação de aves.

Entre os aspectos negativos, está o fato de que os observadores de aves podem modificar o habitat ou provocar o abandono de ninhos durante o período reprodutivo de algumas espécies. A utilização do play back pode estressar as aves durante o período de reprodução além de expor os ninhos a predadores. Também observa-se efeito negativo ao executar gravações com vozes de aves predadoras.(FARIAS, 2007; PIVATTO; SABINO, 127)

Partindo-se do princípio de que as aves e seu habitat constituem o recurso básico para o desenvolvimento do turismo ornitológico, é fundamental a preocupação com esse recurso, pois se a atividade não é praticada de forma organizada e responsável, pode ocorrer uma degradação do meio ambiente e seu consequente desaparecimento. E, neste sentido as aves são excelentes indicadores da "saúde" ambiental do ecossistema.

Uma das medidas mais necessárias para a conservação tanto das aves quanto de seu habitat é obter o apoio da população local, o que se obtém em primeiro lugar, levando -os a compreender o valor do recurso, com o qual convivem diariamente. A educação e conscientização da comunidade local deve se iniciar com as crianças que desde cedo devem aprender a interpretar a realidade ambiental que os rodeia, com a introdução de conhecimentos mínimos de identificação da fauna e da flora. A formação de guias locais de identificação das aves é outra medida que não só contribui para a conscientização local, como propicia o monitoramento das espécies que frequentam a localidade, possibilitando que residentes e turistas tornem-se auxiliares preciosos do trabalho científico de preservação realizado pelos especialistas.

Segundo relato de pesquisadores norte-americanos um dos problemas que limitam o crescimento da observação de aves na Amazônia é a ausência de guias qualificados. A experiência e o conhecimento limitado dos guias têm afetado o desenvolvimento do ecoturismo na Amazônia, dado que em torno de $70 \%$ dos turistas que para lá se dirigem preferem ver vida selvagem, mas devido à densidade da Mata Amazônica não podem ter acesso visual às aves raras, sendo que viajaram milhares de quilômetros e gastaram miIhares de dólares para vê-las. Os guias que em geral conhecem menos do que os obser- 
A biodiversidade como atrativo turístico: o caso do Turismo de Observação de Aves no município de Ubatuba (SP).

vadores amadores de aves estrangeiros contribuem para este tipo de problema (SCHEMO, 1999 apud CHE, 2004).

A prática de observação de aves também permite identificar espécies-bandeira (DIETZ et al., 1994) que são aquelas que apresentam características singulares, quer seja o canto, plumagem, coloração, dança etc; que a tornam espécie carismática para o público em geral, podendo ser utilizadas para incentivar a proteção de determinada área, ecossistema ou uma região específica.

A identificação de um destino turístico com uma espécie bandeira,quer esta seja uma ave, um mamífero, réptil ou anfíbio é importante pela associação imediata do turista com a vida selvagem o que implica em identificação com o mundo natural e qualidade de vida que permite inclusive a existência de espécies silvestres convivendo de algum modo com a presença humana. Um exemplo desse tipo é a adoção pelo distrito turístico de São Francisco Xavier, em São Jose dos Campos/SP do muriqui (Brachyteles arachnoides) também chamado mono-carvoeiro, como animal símbolo da cidade (DSFX,s/d)

Com o objetivo de se estabelecer uma identidade nacional e internacional, um projeto de atração de observadores de aves, deve identificar espécies emblemáticas para torná-las símbolos na apresentação da atividade. A utilização de uma ave como símbolo ajudará a diferenciar e posicionar o município. Podem ser escolhidas espécies raras ou ameaçadas, a mais comum na localidade, uma espécie carismática que se destaca pela beleza de suas penas, de seu canto ou outra característica acentuada.

Uma das características mais importantes da observação de aves é a possibilidade de desenvolvimento de uma "ciência cidadã", na qual milhares de observadores coletam dados para um ramo da ciência. De acordo com Howard Youth (2001), há programas bastante antigos de ciência cidadã como o Christmas Bird Count ( Contagem de aves no Natal), que é patrocinado pela Audubon Society e que ocorre há 100 anos, sendo que em dezembro de 1999 e janeiro de 2000 participaram mais de 50.000 observadores de aves. Há outros projetos semelhantes nos Estados Unidos, Canadá, Espanha, Reino Unido e Austrália.

Embora no Brasil o Turismo de Observação de Aves tenha se expandido lentamente, ha inúmeras iniciativas que projetam para um futuro próximo um incremento desse segmento turístico. Em Minas Gerais, por exemplo, se desenvolve um programa para observação de animais e plantas, denominado "Minas Silvestre", que tem a pretensão de atrair turistas, principalmente estrangeiros para essa atividade. O programa visa a inserção das comunidades locais das áreas contempladas visando a distribuição de renda. A iniciativa tem o apoio da Belotur (Empresa Municipal de Turismo de Belo Horizonte), Secretaria Estadual de Meio Ambiente/Instituto Estadual de Florestas(Semad/IEF) e Secretaria Estadual de Turismo (Setur). Inicialmente estão incluídos os parques estaduais de Ibitipoca, Itacolomi, rio Doce, rio Preto, Brigadeiro e Rola Moça. Também as RPPN (Reservas Particulares de Patrimônio Natural) como o Caraça (DURÃES,2010).

O programa mineiro pretende realizar um amplo inventário das espécies do Estado, elaborar cadastro de integrantes do programa, trabalhar projetos integrados ou autônomos, estabelecer uma rede de núcleos socioambientais, estruturar comunidades, e um 
programa de comunicação e marketing nacional e internacional.

Além da Amazônia, Pantanal e Foz do Iguaçu que são os locais principais da visitação internacional atual de observadores de aves, com frequência cada vez maior são mencionados no Rio de Janeiro, o Parque Nacional de Itatiaia; e em São Paulo, o Parque de Intervales e o município de Ubatuba.

\section{Ubatuba reserva de Mata Atlântica}

O município de Ubatuba com população estimada em 81.096 habitantes (IBGE, 2009) situado a $230 \mathrm{~km}$. da cidade de São Paulo, é um dos mais tradicionais destinos balneários do Estado, recebendo milhares de turistas durante a alta estação. Apresenta praias limpas localizadas na borda da Mata Atlântica, remanescente florestal que é considerado um dos mais importantes biomas do mundo pela sua alta biodiversidade.

A Mata Atlântica, que ocupa $85 \%$ da área do município de Ubatuba, é considerada também como um dos biomas mais ameaçados do mundo devido às constantes agressões nos seus variados habitats. Distribuída ao longo da costa atlântica do Brasil, envolvendo partes do Paraguai e Argentina, correspondia originalmente a $15 \%$ do território brasileiro. Nessa extensa área vive a maior parte da população do país, 112 milhões de habitantes, que perfazem $61 \%$ da população. (FUNDAÇÃO SOS MATA ATLÂNTICA/ INPE, 2009).

Desde o início da colonização europeia com a exploração de seus recursos naturais, seguida da posterior industrialização, a qual correspondeu uma intensa ocupação urbana, a Mata Atlântica teve sua vegetação original drasticamente reduzida. O processo acentuou-se nas últimas décadas. O resultado é que hoje esse remanescente florestal está entre os biomas mais ameaçados de extinção. Segundo dados da Fundação SOS Mata Atlântica(s/d), o bioma foi reduzido a 7\% de sua cobertura original, e abriga hoje 383 dos 633 animais ameaçados de extinção no Brasil.

Sua riqueza faunística é enorme; de acordo com estudo do Ministério do Meio Ambiente (MMA/SBF, 2002) entre os vertebrados existem 250 espécies de mamíferos(dos quais 55 endêmicas), 340 de anfíbios(90 endêmicas), 1023 aves(188 endêmicas), 350 peixes (133 endêmicas) e 197 répteis (60 endêmicos). Esses números são modificados constantemente pela descoberta e redescoberta de espécies, tais como o veado bororó (Mazama bororo) identificado em 1996, o macaco prego galego (Cebus flavius) redescoberto após permanecer 300 anos desaparecido e as aves tapaculo-ferreirinho (Scytalopus pachecol) e o bicudinho do brejo (Stymphalornis acutirostris) mais recentemente.

A importância do bioma é reconhecida tanto nacional como internacionalmente, com trechos significativos sendo reconhecidos como Patrimônio Mundial pela ONU e indicados como Sítios Naturais do Patrimônio Mundial e Reserva da Biosfera da Mata Atlântica pela UNESCO, além disso, foi considerada como Patrimônio Nacional pela Constituição Federal de 1988. (FUNDAÇÃO SOS MATA ATLÂNTICA/INPE, 2009).

$\mathrm{Na}$ área de Ubatuba são encontradas 514 aves diferentes, somente no bairro FoIha Seca, convivem 21 espécies de beija-flor (BALAZINA, 2009). Uma ave rara, o tiê- 
A biodiversidade como atrativo turístico: o caso do Turismo de Observação de Aves no município de Ubatuba (SP).

coroa (Calyptura cristata) foi encontrada no local e foi avistada apenas duas vezes em cerca de 200 anos. Era considerada extinta, mas foi vista pelo alemão Martin Schaeffer, no início de 2008 e confirmada por outro pesquisador (ZANELLI, 2009).O número de aves de Ubatuba representa cerca de $10 \%$ das espécies encontradas na América Latina.

\section{O Turismo de Observação de Aves em Ubatuba}

A Prefeitura Municipal de Ubatuba(PMU) a partir de 2004 desenvolveu projeto sobre observação de aves cujo objetivo é incentivar a população local a preservar a biodiversidade e atrair mais turistas. Para isso, são efetuadas palestras junto a comunidades tradicionais visando o entendimento de que a observação de aves pode ser um importante atrativo turístico e fonte de geração de emprego e renda. As pessoas aprendem a receber os observadores de aves e tem a opção de se tornarem guias, ou explorarem a atividade artesanal relacionada com o tema e abrir novos caminhos para observação (PMU, 2007a)

Em 2004 foi aprovada lei que instituiu como símbolo do município o pássaro Tangará-dançador (Lodopleura pipra) encontrado principalmente no Bairro Taquaral da localidade. A cidade foi incluída no Dia Mundial de Observação e contagem de Pássaros, comemorado dia 4 de outubro, e que é promovido pela Birdlife International, organização mundial de observadores, com sede em Londres (BURHAN, 2005).

Em 2006 teve início o Festival de Observação de Aves, com periodicidade anual, promovido pela Prefeitura onde são feitas palestras, cursos, premiações diversas e visitas programadas a locais de interesse ornitológico. Entre as principais atividades realizadas está um concurso de fotografias, intitulado "Aves de Ubatuba" e que está dividido em três categorias. A primeira denominada "Registro" visa registrar espécies de difícil observação, e as imagens obtidas devem possibilitar a identificação da espécie. A segunda tem o nome de "Pousada" e premia as fotos que mostram aves em descanso no ninho, em galhos ou alimentadores. E finalmente, a categoria "Em Vôo", em que a ave deve ser fotografada sem manter qualquer contato com o solo (PMU, 2006a).

Durante o Festival de 2006 foi realizado o lançamento de uma apostila de observação de aves dirigida às crianças e iniciantes acima de 10 anos, visando despertar o interesse da observação, tanto nos alunos quanto nos professores.A apostila foi desenvolvida numa parceria da prefeitura com o Conpet/Petrobras, que é um programa nacional de racionalização do uso de derivados do petróleo e do gás natural. Além dessa publicação, com uma tiragem de 10 mil exemplares, foi impresso também um checklist, uma lista com os nomes de todas as aves avistáveis em Ubatuba, com tiragem de mil exemplares também patrocinada por empresas locais (PMU, 2006b).

Em Ubatuba, desde 2008, ocorre a prática da ciência cidadã, pois foi incluída no programa "Censo Neotropical de Aves Aquáticas-CNAA" que ocorre desde 1990 simultaneamente na Argentina, Bolívia, Brasil, Chile, Colômbia, Equador, Paraguai, Peru, Uruguai e Venezuela envolvendo mais de 750 voluntários que realizam contagens no verão e no inverno de cada ano (PMU, 2008a). 
Os alunos das escolas municipais se envolvem com a atividade através do projeto "Abrindo janelas para o mundo" que visa sensibilizar os estudantes na preservação do meio ambiente valorizando as aves do local. O projeto auxilia os professores oferecendo ferramentas para a ampliação de seus trabalhos, como a apostila de observação para crianças (PMU, 2009). Os alunos recebem aulas teóricas, sobre como utilizar binóculo e como reconhecer os pássaros pelas cores e sons.

São ministradas palestras nas comunidades tradicionais que vivem em locais com potencial para se tornarem rotas de observação.

Há um envolvimento do empresariado de Ubatuba na atividade de observação de aves, que é vista como uma alternativa para atração de turistas á cidade durante o ano todo. O presidente da Associação Comercial e Industrial de Ubatuba (ACIU), Ahmad Khalil Barakat, considera que é preciso se "investir em mais esse nicho para atrair turistas na baixa temporada. A observação de aves certamente tem potencial para atrair um turismo de qualidade durante o ano todo" (PMU, 2007b).

Como um exemplo do envolvimento dos empresários, os proprietários do hotel Resort Cabreúva, localizado na Praia de Itamambuca tiveram a ideia de registrar o número de aves no entorno, incluindo o rio e a praia. Foram três anos de levantamento, em que foram identificadas 184 aves. Em todo o hotel, existem fotos das aves encontradas na região. Foram instalados comedouros em diversos pontos estratégicos, o que facilitou a aproximação e a procriação das aves no local. No hotel há um barco elétrico, especialmente adaptado para não produzir ruído ou poluição, que serve para subir o rio com os clientes interessados, facilitando a realização de estudos ambientais associados com as aves (PMU,2008b).

Durante a realização do Avistar Brasil, maior evento de observação de aves do Brasil, o stand de Ubatuba contou com a participação de vinte empresas entre hotéis, pousadas e restaurantes, da Associação Comercial, do Sindicato dos hotéis e da associação dos restaurantes (PMU,2007b).

Um fato importante, demonstrando a necessidade de coordenação do poder público, se relaciona com a produção artesanal local. No início do projeto percebeu-se que os turistas estrangeiros não adquiriam o artesanato local, que representava as aves, porque não apresentavam fidelidade com o pássaro original. Foram feitas palestras com os artesãos e artistas artesanais locais para que quando incluíssem o tema "aves de Ubatuba" o fizessem levando em consideração essa necessidade. Hoje a Fundação de Arte e Cultura de Ubatuba realiza esse trabalho de conscientização, ministrado por uma bióloga, estabelecendo até a morfologia das espécies retratadas (A SEMANA, 2006).

\section{Conclusão}

O município de Ubatuba apresenta uma grande complexidade em seu ambiente natural, que se reflete em sua biodiversidade e abundancia de aves, que constituem um importante atrativo para os visitantes. Ao desenvolver uma oferta baseada na observação de aves, contribuiu para o aumento do conhecimento local da fauna, o que possibilitou 
um crescimento do interesse pela atividade, motivando a conservação e envolvendo diversos segmentos da sociedade, desde empresários, populações tradicionais e os alunos das escolas do município.

A exploração da temática "aves" para o turismo permitiu o desenvolvimento de atividades fora do período de alta temporada e envolvendo um público diferenciado, que permanece mais tempo na localidade, apresenta hábitos saudáveis e tem a particularidade de se tornarem multiplicadores para a vinda de novos turistas, pois denotam satisfação pelo que observam enquanto permanecem na localidade.

A observação de aves tem se mostrado como uma atividade turística altamente positiva para o município, controlada e coordenada pelo poder público, que organiza e se faz presente nos eventos relacionados com a observação de aves, articulando a participação dos segmentos empresariais. Estes compreendem que o fluxo turístico permanecerá na medida em que há ocorrência de aves em suas imediações, o que contribui para que mantenham a qualidade ambiental das imediações de seu empreendimento.

O Turismo de Observação de Aves no município de Ubatuba se constitui em uma oferta complementar ao turismo de sol e praia, atraindo um segmento de visitantes de alto poder aquisitivo, formado por estudiosos de aves e que contribuem para a sustentabilidade do ecossistema local.

\section{Referências Bibliográficas}

A SEMANA. Carlos Rizzo, dedicação com a natureza. Jornal A Semana. 15 novembro de 2006, ano 8, n. 300. Disponível em: http://www2.uol.com.br/jornalasemana/net301/ sub9.htm Acesso: 12 abril 2010.

BALAZINA, A. Terra de aves, Brasil desperdiça potencial turístico de observação. Folha de São Paulo on line. 12 jan 2009. Disponível em: http://www1.folha.uol.com.br/ folha/ambiente/ult10007u488927.shtml Acesso: 5 abr 2010.

BOO, E.. Ecotourism: the potential and pitfalls. Vol.2. WWF, Washington,1990.

BRASIL. Ministério do Turismo. Plano Aquarela: marketing turístico internacional do Brasil.Embratur/Mintur, Brasília,2005

BURHAN, S. Ubatuba usará pássaros para atrair turistas estrangeiros. Vale Paraibano, 01 de maio de 2005 - edição on line disponível em http://jornal.valeparaibano.com.br acesso: 20 agosto de 2006.

CHE, D. Guided birding tours: an examination of the market, important tours parameters, and participant demographics. In: MURDY, J. (comp.), 2004. Proceedings of the 2003 Northeastern Recreation Research Symposium. Gen. Tech.Rep.NE-317, Newton Squarte, PA: US Department of Agriculture, Forest Service, Northeastern Reserarch Station. pp. 194-202. 2004.

CORDELL, H.K.; HERBERT, N.G. The popularity of birding is still growing. Birding. 34:54 -59.2002 . 
Dias, $R$.

DIETZ, J.M.; DIETZ, L.A.; NAGAGATA, E.Y. The effectiva use of flagship species for conservation of biodiversity: the example of lion tamarins in Brazil. In: Olney, P.J.S.,Mace,G.M;Feistner,A.T.C.(eds). Creative conservation: interactive management of wild and captive animals. London:Chapman and Hall, 1994.pp.32-49.

DSFX - DISTRITO DE SÃO FRANCISCO XAVIER - São Francisco Xavier disponível em: http://www.saofranciscoxavier.org.br/meioambiente.htm acesso em: 3 abr 2010.

DURÃES, Alfredo. Olhar para o futuro. Estado de Minas. Caderno Turismo. pp. 04-07, 09 março 2010.

EDROMA, E.L. Vida Silvestre, turismo y otros productos de los espacios naturals. In: Fauna Silvestre, turismo y otros productos de lás áreas silvestres. XI Congreso Forestal Mundial, Anatolya/ Turquia: FAO(Food na Agriculture Organization of the United Nations), 13 a 22 oct. 1997, v. 3, tema 18, 1997.

FARIAS, G.B. A observação de aves como possibilidade ecoturística. Revista Brasileira de Ornitologia, n. 03, vol.15, p. 474-477. Setembro de 2007.

FUNDAÇÃO SOS Mata Atlântica. Mata Atlântica(s/d). Disponível em: www.sosmatatlantica.org.br. Acesso: 5 abril 2010.

FUNDAÇÃO SOS Mata Atlântica/Instituto Nacional de Pesquisas Espaciais - INPE. Atlas dos remanescentes florestais da Mata Atlântica e ecossistemas associados no período 2005-2008. Relatório parcial. São Paulo: Fundação SOS Mata Atlântica/INPE, 2009.

IBGE - Instituto Brasileiro de Geografia e Estatística. Estimativas das populações residentes, em 01 de julho de 2009, segundo os municípios. Brasília: IBGE, 2009. Disponível em: www.ibge.gov.br Acesso: 03 mai 2010.

LINDBERG, K. Policies for maximizing nature tourism's ecological and economical benefits. World Resources Institute: Washington,1991. p.37

SCHEMO, D.J. Why eco-tourists are shunning Brazil. New York Times, 24 jan. 1999: 5, 3:1, 1999.

MMA/SBF- MINISTÉRIO DO MEIO AMBIENTE/SECRETARIA DE BIODIVERSIDADE E FLORESTAS. Biodiversidade brasileira: avaliação e identificação de áreas e ações prioritárias para a conservação, utilização sustentável e repartição dos benefícios da biodiversidade nos biomas brasileiros. Brasília: MMA, 2002.

PIVATTO, M.A.C.; SABINO, J. Recomendações para minimizar impactos à avifauna em atividades de turismo de observação de aves. Atualidade Ornitológicas, n. 127.Setembro/Outubro de 2005. Disponível em: www.ao.com.br Acesso: 25 abril 2010.

PMU. Prefeitura Municipal de Ubatuba. Ubatuba realiza I Festival de Observação de Aves. Notícias de Ubatuba.20 de outubro de 2006a. http://www.ubatuba.sp.gov.br acesso: $22 / 04 / 2010$

PMU. Prefeitura Municipal de Ubatuba. Ubatuba lança apostila de observação de aves para crianças. Click Litoral. 10 nov 2006b. Disponível em: http:// www.clicklitoral.com.br/02340.html Acesso: 04 abr 2010. 
PMU - Prefeitura Municipal de Ubatuba. Prefeitura ensina observação de aves para alunos especiais e comunidades tradicionais. O Guaruça. Ubatuba/SP. 05 de maio de 2007a. Disponível em http://www.ubaweb.com/revista. Acesso: 06/05/2010.

PMU - Prefeitura Municipal de Ubatuba. Ubatuba participa do maior evento de observação de aves do Brasil. Notícias de Ubatuba. 25 de maio de 2007b. http:// www.ubatuba.sp.gov.br Acesso: 06/05/2010.

PMU - Prefeitura Municipal de Ubatuba. Ubatuba realizará censo das aves aquáticas. Notícias de Ubatuba.17 de junho de 2008a. http://www.ubatuba.sp.gov.br Acesso: 06/05/2010.

PMU. Prefeitura Municipal de Ubatuba. Ubatuba atinge o marco de 500 espécies de aves registradas. Click Litoral. 11 de julho de 2008b. http://www.clicklitoral.com.br/10129ubatuba-atinge-o-marco-de-500-especies-de-aves-registradas/ acesso: 22 de maio de 2010.

PMU - Prefeitura Municipal de Ubatuba. IV Festival de observação de aves movimentará Ubatuba em outubro. Ubatuba em revista. 17 de setembro de 2009. Disponível em: http://www.ubatubaemrevista.com.br Acesso: 06 de maio de 2005.

SEKERCIOGLU, Ç.H. Impacts of birdwatching on human and avian communities. Environmental Conservation 29(3): 282-289, 2002.

USA (United States of América). Department of the Interior and Wildlife Service and U.S. Departmente of Commerce. National Survey of fishing, hunting and wildlifeassociated recreation. U.S. Department of the Interior, Fish and Wildlife Service/ U.S.,Department of Commerce:Washingotn D.C.2002.

YOUTH, H. Observando x caçando. Revista World Watch. Universidade da Mata Atlântica/World Watch Institute. 2001. Disponível em : www.wwiuma.org.br/ observando cacando.htm. Acesso: 03 abr 2010.

Reinaldo Dias: Centro Universitário UNA e Universidade Presbiteriana Mackenzie Email: reinaldias@hotmail.com

Link para currículo Lattes: http://lattes.cnpq.br/5937396816014363

Data de submissão: 25 de junho de 2010.

Data do aceite: 18 de outubro de 2010. 